\title{
Pemukiman Awal Sungai Kapuas
}

\author{
Yuver Kusnoto a, Yulita Dewi Purmintasari ${ }^{\text {b,1 }}$ \\ a,b Program Studi Pendidikan Sejarah, IKIP PGRI Pontianak \\ 1yulita.dewi46@gmail.com
}

\begin{tabular}{ll}
\hline Informasi artikel & ABSTRAK \\
\hline Kata Kunci: & Penelitian ini bertujuan untuk mengetahui kodisi geografis Kalimantan \\
Pemukiman, Sungai & Barat dan Sungai Kapuas, dan mengetahui pola pemukiman \\
Kapuas, Kalimantan & masyarakat Kalimantan Barat di sepanjang Sungai Kapuas. \\
Barat & Metode yang digunakan dalam penelitian ini adalah metode sejarah. \\
& Metode sejarah adalah prosedur sejarawan Untuk melukiskan kisah \\
& masa lampau berdasarkan jejak-jejak yang ditinggalkan pada masa \\
& lampau dengan langkah-langkah penulisan sejarah sebagai berikut: (1) \\
& heuristik, (2) kritik, (3) interpretasi dan (4) historiografi. \\
& Berdasarkan penelitian yang dilakukan maka dapat ditarik kesimpulan \\
& bahwa: (1) sebagian besar di wilayah borneo barat ditutupi oleh hutan- \\
& hutan tropis, dan aliran-aliran sungai yang panjang. Sungai-sungai \\
& tersebut merupakan jalur transportasi penghubung antar daerah. Sungai \\
& merupakan sumber kehidupan masyarakat borneo. (2) Terbentukanya \\
& pola pemukiman masrayarat di pinggirian aliran sungai kapuas adalah \\
& proses utuk membentuk suatu kawasan yang terencana yang kemudian \\
& dapat mengantur kehidupan masyarakat yang pasti suatu saat nanti \\
& semakin kompleks.
\end{tabular}

Keywords:

Settlement, Kapuas River, West Kalimantan

\section{ABSTRACT}

The research aims to understand condition geographical west kalimantan and kapuas river, and he knows pattern settlement west kalimantan along the kapuas.

Methods used in research this is the method history.A method of history is procedure historian to figure the story of the past based on traces of left in the old time by steps the writing of history as follows: (1) a heuristic, (2) criticism, (3) interpretation and (4) historiografi.

Based on research conducted so a conclusion can be drawn that: (1) the majority of in the borneo west covered by tropical forests, and flows river that long. The rivers is the road transport links between regions.The river is a source of life the community borneo.( 2 ) terbentukanya pattern settlement masrayarat in pinggirian the river kapuas is the process of to form a the planned that can then be mengant.

\section{PENDAHULUAN}

Negara Indoesia dikenal dengan negara kepulauan. Lebih dari 1000 pulau yang berada di indonesia yang terletak diberbagai penjuru negara ini baik dari wilayah barat maupun timur. Kondisi geografis yang hampir dikelilingi air, tidak menutup kemungkinan di daratan juga memiliki aliran air yang begitu banyaknya juga atau yang biasa disebut sungai.

Peradaban manusia, sungai menjadi unsul yang paling penting alam sumber 
kehidupan. Suangai memiliki aliran yang panjang dijadikan sumber kehidupan utama oleh manusia. Seperti mandi, mencuci, dan lain sebaginya mata pencarian. Sungai yang mengalir dan menjangkau ke setiap wilayah menjadikan sungai sebagai jalur untuk berpindah dari tempat yang satu ke tempat lain. Perpindahan tersebut akan membentuk suatu struktur kehidupan yang menjadikan sebuah pemukiman yang awalnya wilayah tersebut tidak berpenghuni, dan menjadi suatu pemukinan yang cukup besar.

Indonesia dulunya dikenal dengan gugusan pulau-pulaunya sehingga disebut dengan Nusantara yang pada saat itu mengalami masa kejayannya sebagai wilayah maritim. Dimasa jayanya ini lah perairan dan laut indonesia menjadi jalur transfortasi perdagangan internasional. Di abad pertengahan, perdangan terbesar dikuasai oleh kerajaan Sriwijaya yang berhasil menguasai semua wilayah di nusantara baik di laut jawa, laut banda, dan wilayah lainnya.

Sejarah indonesia mencatat bahwa sungai dan laut menjadi jalur transportasi utama yang digunakan masyarakat indonesia. Peran kerajaan-kerajaan dinusantara dalam berhubungan dagang ke wilayah nusantara lainnya menggunakan transportasi laut dan sungai. Hubngan antara kerajaan-kerajaan dinusantara tidak hanya dibidang perdangangan, akan tetapi hubungan sosial dalam perkawinan yang menimbulkan efek terhadap aktifitas lainnya seperti penyebaran agama.

Masuknya kolonial atau bangsa asing diindonesia juga melalui transportasi laut seperti yang diungkapkan oleh Riclafh (2008) menyebutkan jalur utama diselat malaka melupakan salah satu jalur utama untuk masuk di wilayah nusantara yang dilakukan oleh bangsa lain untuk melakukan hubungan dagang dengan kerajaan-kerajaan diwilayah tersebut. Jika kita tarik pada masa islamisasi indonesia yang sistem pemerintahan pada masa itu masih didominasi oleh sistem pemerintahan kerajaan. Kerajaan-kerajaan yang ada di wilayah nusantara, menggunakan transportasi suangai dan laut untuk berhubungan dagang dengan masyarakat lainnya.

Kalimantan barat, terdapat sungaisungai yang mengalir melewati wilayahwilayahnya. Sungai Kapuas yang merupakan sungai terpanjang di indonesia ini membentang luas ke penjuru wilayah kalimantan barat. Sungai kapuas dijadikan sumber kehidupan utama bagi masyarakat kalimantan barat. Selain sebagai jalur transportasi, sungai kapuas dijadikan mata pencarian untuk swadaya perikanan, dan juga untuk keperluan rumah tangga lainnya.

Sungai memiliki peran penting dalam kehidupan masyarakat Kalimantan Barat. Sehinga adanya sungai ini akan mempengaruhi keberadapan kehidupan sosal yang terdapat ditepian sungai. Hal ini disebabkan sungai menjadi sasaran perhubungan yang paling memungkinkan saat itu untuk berpindah dari satu tempat ke tempat lain. Penyebaran peradaban manusia di tepian sungai terlihat dari berbagai peninggalan-peninggalan yang ada di daerah aliran sungai.

\section{METODE}

Sejarah sebagai ilmu terikat pada prosedur penelitian ilmiah. Metode penelitian sejarah adalah seperangkat aturan atau prinsip sistematis untuk mengumpulkan sumber-sumber sejarah secara efektif serta melakukan penilaian secara kritis dalam bentuk tulisan.

Menurut Nugroho Notosusanto, tahapan penelitian sejarah terdiri dari heuristik, verifikasi, interpretasi dan penulisan (Notosusuanto, 1975: 35). Heuristik, Langkah awal dalam metode sajarah adalah heuristik menemukan atau mengumpulkan sumber-sumber sejarah yang berupa jejak-jejak masa lampau melalui studi Pustaka, sumber lisan maupun lewat pengamatan lapangan baik yang primer mapun yang sekunder. Verifikasi, Kritik Sumber merupakan kegiatan meneliti untuk menentukan validitas dan reliabilitas 
sumber sejarah melalui kritik ekstern dan intern (Kuntowijoyo, 2003: 100-101). Kritik eksternal dilakukan dengan melihat fisik dokumen yang digunakan, apakah salinan asli atau tidak. Kritik ekstern digunakan pula untuk melihat tanggal, tahun pembuatan dokumen, serta digunakan untuk mencermati tanggal, tahun penulisan dan pengarang pada sumber sekunder. Kritik intern berkaitan erat dengan masalah kredibilitas yang digunakan untuk mengetahui sejauh mana kebenaran sumber tersebut.

Proses interpretasi dibagi dalam dua tahap, yaitu analisis dan sintesis. Dengan interpretasi penulis menafsirkan fakta sejarah yang telah ditemukan yang telah melalui proses verifikasi, dengan demikian hasil penelitian ini akan menjadi sebuah karya sejarah.Historiografi, Historiografi merupakan kegiatan penyampaian sintesis dari penelitian yang ditulis secara kronologis. Historiografi merupakan kegiatan menyusun fakta-fakta menjadi sebuah kisah sejarah setelah melakukan pencarian sumber, penilaian sumber dan penafsiran sumber yang kemudian dituangkan menjadi sebuah kisah sejarah dalam bentuk tulisan.

\section{HASIL DAN PEMBAHASAN}

\section{A. Kondisi geografis Kalimantan Barat dan Sungai Kapuas \\ 1. Kondisi Geografis Kalimantan Barat}

Kalimantan Barat yang merupakan salah satu provinsi di indonesia yang beribukotakan pontianak. Pontianak merupakan jalur masuknya negara luar dalam melakukan perdagangan ataupun wisatawan ke wilayah kalimantan barat. Lokasi yang dilewati garis khatulistiwa ini memiliki karakteristik, sejarah dan budaya yang layak untuk diketahui. Karakteristik masyarakat pontianak beridentitaskan melayu, hal ini tidak lepas dari awal mula kedatangan Sy.Abdurahman al qadri yang membangun kota pontianak ini. Tradisi budaya melayu dikota pontianak semakin waktu semakin berkembang.

Secara umum, kalimanatan barat dikenal dengan nama Borneo, yang dipandang oleh masyarakat dunia merupakan pulau terbesar yang pernah ada. Ada yang berpendapat bahwa pulau borneo ini tiga kali lipat atau lebih dari pulau jawa. Walaupun belum banyak pengetahuan mengenai pulau yang luasa ini belum banyak dituliskan dalam naskah. Perhitungan luas borneo dinyatakan bawah 12.962 mil persegi, dengan demikian luas pulau borneo ini luasnya melebihi luas Negara Peracis yang hhanya 9.748 mil persegi, dan bahkan luas borneo adalah dua puluh sati kali luas negeri belanda (Veth: 37).

Pulau borneo terletak antara 7 derajat LU dan 4,2 derajat LS, serta di antara 100 dan 116 derajat bujur timur. Sedangkan panjang pulau ini diperhitungkan sekitar 250 jam erjalanan dan lebarnya sekitar 200 jam. Wilayah pantai borneo terdapat banyak teluk-telu yang menjorok ke dalam, sehingga panjang garis pantainya banyak hal kurang dibandingkan dengan panjang garis pantai pulau jawa atau sumatra. Walaupun demikian kekurangan itu bisa ditutup dengan keberadaan sungai sungai yang indah, namun menjadikannya kurang cocok untuk pelayaran laut.

Pulau borneo ini memiliki daerah pedalaman yang sangat luas yang sebagian besar belum dikenal yang hanya bisa dikenal melaui kunjungan penjelajahan yang memakan waktu yang cukup lama.

a. Kependudukan

Belum diketahui berapa besar jumlah jiwa yang pasti pada penduduk di kaliamantan, dan terutama di pesisir sungai kapuas. Hasil temuan oleh tuan Melvill van Carnbee (dalam V.J. Veth) menyebutkan jumlah penduduk hanya mencapai 810.000 jiwa. Sulit untuk dikatakan valid dalam perhitungan ini, bahkan didaerah pesisir pantai sekalipun jumlah penduduknya belum 
dapat diperkiraan. Hal ini dikarenakan besarnya luas tanah borneo ini.

Kependuduan di tanah borneo dapat di bagi menjadi beberapa golongan, yatitu, dayak, melayu, dan china atau tionghoa. Dayak dapat dikatakan melayu tua, atau lebih dikenal juga sebagai suku asli orang kalimantan barat. Masih dengan data yang digunakan melviin suku dayak berjumlah setengah juta jiwa dari seluruh jumlah yang ada di borneo. Masyarakat dayak berada di daerah pendalaman pulau borneo ini, dan masyarakat terpecah menjadi sukusuku dah hidup di tepi-tepi sungai dan bergantungan pada hutan alam borneo yang kaya raya.

Masyarakat melayu borneo yang merupakan penganut aga islam pada umumnya, dan bercampur pada orang jawa, bugis, dan sejublah petualang arab. Hampir bagian besar masyarakat melayu berada di ketemian pantai borneo, terutama didaerah pesisir laut dan pesisir muara sungai.

Masyarakat China, mayoritas china yang ada di borneo merupakan pendatangm dan meraka bermukim hampir di pesisir pantai borneo. Usaha yang dilakukan berupa pertambangan emas yang berada di perdalaman borneo, ada juga yang berdagang.

b. Iklim

Pulau borneo dibelah oleh garis khatulistiwa yang menjadikan pulau ini bagian utara dan bagian selatan. Secara umum iklim di borneo tidak begitu gerah dan dapat dikatakan sedang. Di pulau borneo kelembawan dapat dikatakan cukup tinggi dan suhu udara umumnya adalah dingin. Kota pontianak yang letaknya berada di bawah garis khatulistiwa memili rata-rata 32-28 derajad celcius pada siang hari, dan mengalami dingin di malam hari.

Musim kemarau dan musim penghujan di borneo dapat dikatakan stabil. Musim kemarau berada di bulan agustus hingga maret, dan penghujan di bulan maret hingga ke juli. Perkiraan cuaca seperti ini dimanfaatkan baik oleh masyarakat untuk berladang.

c. Keadaan tanah dan sungai

Struktur tanah dari pulai ini intuk sebgaian belum diketahui sepenuhnya. Didaerah pedalaman terutama pada bagiasn sebelah utaranya sebagian besar terdiri serangkaian pegunungan yang mengrarah ke berbagai arah dan sejak dahulu secara umum disebut sebagai orang pegunungan.Didaratan yang luas dan memiliki curah hujan yang sangat stabil menjadikan tanah yang subur. Daratan ini di aliri oleh sungaisungai yang indah dan berkelokkelok, dan dapat dialiri keperdalaman dan bermuara di pantai-pantai disegala penjuru pulau ini.

Wilayah Borneo Barat, sungai utama adalah sungai kapuas atau sungai pontianak sedangkan di sebelah utara terdapat sungai sambas, dan disebelah selatan ada sungai simpang dan sungai pawan.

d. Flora dan fauna

Tanah pulau borneo sangat subur dan bise ditanami dengan semua jenis tanaman ada didaerah tropis. Padi yang menjadi bahan makanan utama penduduk kepulauan Nusantara tumbuh dengan baik. Tanaman tebu juga menhasilkan produksi yang cukup banyak. Tanaman kopi tumbuh dan berkembang baik. Lada merupakan tanaman yang cocok ditanam disini. Tanaman rempah tumbuh dan terdapat dimana-mana sedangkan tanaman tembakau dapat berkembang ila dirawat dengan baik.

Kelapa, pinang, durianm manggism nangkam rambutan dan banyak lagi jenis tanaman buahbuahan dan tanaman perkebunan 
memberikan hasil yang sepadan dengan upaya pemeliharannya. Dengan kata lain dapat dikatakan bahwa tidak ada satu jenis tanaman yagn bernilai, yang tidak bisa tumbuh di tanah Borneo.

Hutan-hutan di borneo merupakan paru-paru dunia, yang menjadikan suhu udara menjadi dinding, dibagian-bagian dari pulau ini yang rendah dan bertanah aluvial, hutan-hutan dibelah oleh begitu banyak sungai dan danau. Tanah delta yang berawa-rawa yang cukup luas. Hal demikian tampak betapa alam diwilayah khatulistiwa ini menampilkan banyak mahkhuk hidup yang berkembang biak didalam hutan borneo.

\section{Kondisi Sungai Kapuas}

Sebagain besar di wilayah borneo barat ditutupi oleh hutan-hutan tropis, dan aliran-aliran sungai yang panjang. Sungaisungai tersebut merupakan jalur transportasi penghubung antar daerah. Sungai merupakan sumber kehidupan masyarakat borneo sehingga ditepi tepian sungai terdapat pemukiman pemukiman penduduk yang didiami oleh masyarakat borneo baik dayak, melayu ataupun cina.

Sungai utama yang mengalir diborneo bagian barat adalah sungai kapuas. Sungai yang mengah ini bersumber di jantung pulai ini, kira-kira kordinat 114 derajat bujur timur. Namun hingga saat ini belum ditemukan orang eropa atau pun setempat menemukan sumber air dari sungai ini. Sungai terpanjang di borneo ini mengalir keperdalaman borneo dan memiliki anak-anak sungai. Jika dilihat secara geografis, sugai kapuas ini mengalir melewati wilayah Pontianak, Kubu, Tayan, Meliau, Sanggau, Sekadau, Sintang, dan wilayah Kapuas Hulu. Jarak-jarak antara titik-titik utama yang dialiri sungai kapuas memperhitung kelokan-kelokan sungai yang besarnya saja masing-masing adalah 84,55 dan 75 Pal.
Sebagai jalur transportasi utama di sungai kapuas, kapal bandong merupakan alat transportasi utama untuk perjalanan ke hulu sungai kapuas. Melihat kedalaman kapuas diantara 20-30 kaki sehingga memungkinkan untuk melakukan perjalanan dengan kapal bandung yang hanya 3-4 kaki. Jika dimusim penghujan, kedalaman air bisa mencapai lebih dari 30 kaki dan mengalami kebanjiran di berada wilayah-wilayah pesisir sungai kapuas.

Diwilayah sintang sungai kapuas bertemu dengan sungai melawi, yang merupakan cabang terbesar dari sungai kapuas. Sungai ini dekanal dengan sungai simpang kanan yang mengarah ke Nanga Pinoh. Sedangkan sungai yang mengarah ke Hulu sungai (kapuas hulu) disebut dengan simpang kiri. Sungai kapuas tersebut akan mengalir ke anak sungai baru yang ditemui diperdalaman borneo dapat dikatakn cukup banyak. Hampir ditiap daerah memiliki anak cabang kapuas, atau anak sugai yang langsung bermuara ke sungai kapuas.

Sepanjang aliran sungai kapuas ini terdapat sejumlah besar sungai-sungai yang mengalir dari pegunungan yang membatasi daerah aliran sungai yang menuju ke sungai kapuas. Sehingga jika keadaan tersebut mengakibatkan volume air sungai kapaus akan bertambah dan akan dibawa ke laut. Diantara banyak anak sungai yang bermuara ke sungai kapuas, akan dijumpai warna-warna sungai yang bermacammacam juga. Ada yang berwarna hitam pekat, coklat tua, coklat, dan kehijuan. Hal ini diakibatkan karena berbagai macam sifat-sifat tumbuhan-tumbuhan yang terdapat di hutan yang dilewati sungai.

\section{B. Pemukiman Awal Sungai Kapuas}

Para filsuf sejarah mengatakan bahwa sejarah adalah dialektika antara kontinuitas dan diskuntinuitas, suksesi antara order dan change, atau semboyan yang terkenal dari soekarno sejarah adalah semacam simponi revolusioner dari usaha menjebol dan membangun, bila dihubungkan dengan kebudayaan akan ada 
dialek dua dimensi kebudayaan. Menurut Kleden, bahwa kebudayaan adalah dialek antara ketenangan dengan kegelisahan, antara penemuan dan pencarian, antara integritas dan disintegritas, antara tradisi dan reformasi. Karena tanpa traisi atau tanpa integrasi suatu kebudayan menjadi tanpa identitas sedangkan tanpa reformasi atau disintegrasi suatu kebudayaan akan kehilangan kemungkinan-kemungkinan untuk berkembang, untuk memperbahauri diri, atau untuk menyesuaikan diri dengan paksaan perubahan sosial (Kleden,1986).

Tidak ada sumber yang betul-betul memadai untuk menggambarkan bagaimana bentuk pemukiman awal masyarakat tradisional Kalimantan Barat yang mendiami pinggiran sungai kapuas. Sebaran dan bentuk pemukiman yang ada di kabupaten dan kota dan kecamatan yang ada di Kalimantan Barat merupakan hasil dari proses pemikiran manusia dalam menciptakan ruang kehidupannya sesuai dengan kondisi, site, geografis, terus berkembang sesuai dengan alur sejarah yang mengikutinya. Pemukiman ini lahir dipengahruihi oleh adat istiadat, agama, matapencaharian dan bidang kehidupan lainnya dengan kodisi yang alamiah, sehingga sehingga lahir satu pola kota organik yang beroirentasi pada alam. Dan mempunyai pola sosial yang kuat dan unik.

Terbentukanya pola pemukiman masrayarat di pinggirian aliran suangi kapuas adalah poroses utuk membentuk suatu kawasan yang terencana yang kemudian dapat mengantur kehidupan masyarakat yang pasti suatu saat nanti semakin kompleks. Salah satu bentuk konsep yang terlihat pada pola penggunaan tanah yang merupakan struktur serta faktor yang mempengaruhinya. Ada beberapa bentuk atau pola pemukiman awal masyarakat di sepanjang sungai kapuas beserta anak-anak sungainya:

1. Pola mengelompok

Dareah pemukiman cenderung tumbuh secara mengelompok pada pusat kegiatan. Perumahan tumbuh secara tidak terencana, hal ini menyebabkan keseimbangan alam terganggu. Jika pertumbuhan tidak terkendali maka daerah dekat pusat kegiatan menjadi padat dan cenderung menjadi daerah yang kumuh. Berdasarkan hasil observasi pola seperti ini terjadi di daerah danau, daerah aliran sungai, muara. Pusat pemukiman oleh sebagian besar masyarakat kailmantan barat diknal dengian istilah nanga. Tidak jarang kata nanga akhirnya dijadikan nama daerah.

2. Pola menyebar

Pada pola ini daerah pemukinanya tumbuh tersebar, sehingga jangkauan fasilitas umumnya sulit dan tidak merata.

3. Pola memanjang

Daerah pemukiannya tumbuh mengikuti tepian-tepain sungai, dan danau. Sehinga terbentuk pemukimanpemukiman linier disepanjang tepian. Jika pertumbuhan pemukiman ini tidak terkendali maka kelestarian sumber daya alam yang terancam rusak (Kusnoto dan Firmasyah, 2015:78).

Aliran Sungai kapuas memiliki anak-anak sungai. Anak-anak sungai ini berfunsi sebagai penghubung permukiman dengan daerah penghasil komoditas pertanian dan barang-brang perdangan lainnya. Pola sungai seperti ini menarik bagi masyarakat awal di tepi sungai kapuas membentuk pola pemukiman mengelompok dan memanjang mengikuti aliran sungai kapuas mapun anak-anak sungai (kanal/parit) (Hasanuddin, 2014: 39).

Secara umum menurut Ethoven (Sjamsudin, 2013: 32) daerah aliran sungai kapuas dibagi atas tiga bagian besar yaitu bagian atas atau hulu yaitu dari ujung paling atas sungai sampai ke kota putus sibau. Bagian kedua, dari putus sibau ke hilir sampai ke Tayan terbentuk delata, dari tayan sampai kel muara sungai aau laut disebut sungai bawah atau hilir. Pola pemukiman masyarakat dari Ketiga bagian sungai kapuas ini memilki ciri masing- 
masing dan berkembang sesuai dengan pola pemerintahan yang berkuasa pada masa itu.

Beberarpa pola pemukiman awal yang berada di bagian hulu sungai kapuas seperti bunut sebagian besar masih sangat sederhana, kecil dan terbuat dari bahan bangunan yang tidak tahan lama (kayu dengan kualitas rendah, kulit kayu unyuk atap, dan bambu. Untuk menyesuaikan dengan pasang surutnya air sungai rumah dibuat bertiang. Sementara satu-satunya penghubung antar rumah dibuat pangkalan yang sederhana. Pola lain masyarakat Bunut di tepi sungai tebaung anak sungai kapuas untuk satu rumah bisa di diami delapan keluarga yang juga sangat sederhana (Ethoven dalam Vandijk, 2016:32).

Berkembangnya pemukiman di sepanjang aliran sungai kapuas disebabkan oleh beberapa faktor yaitu, ; a) sungai sebagai satu-satunya jalur transportasi yang efektif ke dunia luar atau sebaliknya; b) sungai sebagai sumber penghidupan (pertanian, hasil hutan dan lain-lain) fungsi sungai seperti ini kebanyakan ada di bagian hulu, sementara di bagian tengah dan hilir lebih dipergunakan sebagai alat transportasi dan perikanan karena tanahnya berawahrawah; c) dimuara-muara sungai tempat bertemunya golongan masyarakat yang beraneka ragam sehingga kondisi ini memungkinkan bagi masyarakat untuk bermukim untuk menambah interaksi dengan dunia luar. Hanya saja untuk muarasungai tidak semua bisa di tempati oleh masyarakat awal tepian sungai kapuas. Sebagai contoh Untuk wilayah muara sungai kapuas terutama di tepian kanan sungai kapuas tidak banyak ditempati penduduk karena diperuntukan untuk perkebunan kelapa mulai dari batulayang sampai ke Peniti Besar. Selain itu jug diperuntukan sebagai lahan sawah. Karena wilayah sudah berdekatan dengan laut apabila terjadi pasang maka air akan meluap, meskipun sudah dibangun terusan tetapi tetap tidak bisa menampung air pasang. Kondisi lahan seperti ini tidak menguntungkan bagi penduduk untuk menempati wilyah tersebut Ethoven dalam (Vandijk, 2016:259).

Berkembangnya tepian sungai kapuas sebagai pusat keramaian dengan berbagai pola sistem yang terbentuk ini Sehingga tidak mengherankan jika di beberapa wilayah pinggiran sungai kapuas terbentuk kerajaan-kerajaan melayu yang cukup berpengaruh dalam perkembangan masyarakat Kalimantan Barat seperti tayan, meliau, sangggau, sekadau, Sintang, Silat, Selimbau, Piasa, Suhaid, Jongkong, dan Bunut Ozinga (Sjamsuddin, 2013: 49).

Untuk menjalin komunikasi antar rumah pada pemukinan masyarakat dibangun jembatan-jembatan kecil atau istilah masyarakat setempat geretak. bahannya terbuat dari kayu, biasanya kayu belian. Lebar geretak ini rata-rata antara 11,5 meter dengan tinggi 2 sampai 3 meter diatas permukaan air.pembatan geratk dahulunya sudah melalui perhitungan dan kearifal yang baik oleh masyarakat. Pada bagian tengah bangunan geretak ini agak meninggi agar perahu-perahu atau alat transportasi lainnya bisa melewatinya.

\section{SIMPULAN}

Berbicara tentang Sungai Kapuas di Kalimantan Barat sangat menarik, maka dari itu berdasarkan hasil penelitian yang telah dipaparkan maka dapat ditarik benang merah penelitian yang berjudul Peradaban Sungai Kapuas, yaitu bahwa sebagian besar di wilayah borneo barat ditutupi oleh hutanhutan tropis, dan aliran-aliran sungai yang panjang. Sungai-sungai tersebut merupakan jalur transportasi penghubung antar daerah. Sungai merupakan sumber kehidupan masyarakat borneo sehingga ditepi tepian sungai terdapat pemukiman pemukiman penduduk yang didiami oleh masyarakat borneo baik dayak, melayu ataupun cina. Sungai utama yang mengalir di borneo bagian barat adalah sungai kapuas

Terbentukanya pola pemukiman masrayarat di pinggirian aliran sungai kapuas adalah proses utuk membentuk suatu kawasan yang terencana yang 
kemudian dapat mengantur kehidupan masyarakat yang pasti suatu saat nanti semakin kompleks. Salah satu bentuk konsep yang terlihat pada pola penggunaan tanah yang merupakan struktur serta faktor yang mempengaruhinya.

\section{DAFTAR PUSTAKA}

Gottschalk, Louis. 1975. "Understanding History: A Primer of Historical Method", a.b, Nugroho Notosusanto, Mengerti Sejarah. Jakarta: Universitas Indonesia Press.

Hassanudin. 2014. Pontianak Masa Kolonial. Yogyakarta: Ombak.

Ignas Kleden. 1986. Membangun Tradisi Tanpa Sikap Tradisional Dilema Indonesia Antara Kebudayaan dan Kebangsaan. Majalah Prisma, edisi no. 8 tahun 1986 .

Kuntowijoyo. 2003. Metodologi Sejarah. Yogyakarta: Tiara Wacana.

Kusnoto, Yuver dan Firmansyah, Haris. 2016. Eksistensi Istana Kerajaan di Kalimantan Barat sebagai Sumber Belajar Sejarah. Jurnal Historia, Vol 4 No 1, Tahun 2016.

Riclafh. 2008. Sejarah Indonesia Modern. Yogyakarta: Gadjah Mada University Press.

Sjamsuddin,Helius. 2013. Perlawanan dan Perubahan di Kalimantan BaratKerajaan Sintang 1822-1942. Yogyakarta: Ombak.
Vandijk (dialih bahasakan oleh P.Yeri). 2016. Hubungan-hubungan VOC dengan Succadana, Sambas dan Landak 1600-1660. Yogyakarta: Penerbit Pohon Cahaya.

Veth.P.J. 2012. Borneo Bagian Barat: Geografsi, Statistik, Historis Jilid 1, Terjemahan Borneo's westerAfdeeling,Geographisch, Statistisch, Historisch voorafgegaan door eene algemeene schets des ganschen eilands a.b P.O.C.Yeri., Pontianak: Isntitut Dayakologi. 